\title{
A COMPARATIVE STUDY OF THE PRIMARY VASCULAR SYSTEM OF CONIFERS. III. STELAR EVOLUTION IN GYMNOSPERMS ${ }^{1}$
}

\author{
Kadambari K. Namboodiri² and Charles B. Beck \\ Department of Botany, University of Michigan, Ann Arbor
}

$\begin{array}{lllllllllllll}\text { A } & \text { B } & \mathbf{S} & \mathrm{T} & \mathbf{R} & \mathrm{A} & \mathrm{C} & \mathrm{T}\end{array}$

\begin{abstract}
This paper includes a survey of the nature of the primary vascular system in a large number of extinct gymnosperms and progymnosperms. The vascular system of a majority of these plants resembles closely that of living conifers, keing characterized, except in the most primitive forms which are protostelic, by a eustele consisting of axial sympodial bundles from which leaf traces diverge. The vascular supply to a leaf originates as a single trace with very few exceptions. It is proposed that the eustele in the gyr.nosperms has evolved directly from the protostele by gradual medullation and concurrent separation of the peripheral conducting tissue into longitudinal sympodial bundles from which traces diverge radially. A subsequent modification results in divergence of traces in a tangential plane. The closed vascular system of conifers with opposite and whorled phyllotaxis, in which the vascular supply to a leaf originates as two traces which subsequently fuse, is considered to be derived from the open sympodial system characteristic of most gymnosperms. This hypothesis of stelar evolution is at variance with that of Jeffrey which suggests that the eustele of seed plants is derived by the lengthening and overlapping of leaf gaps in a siphonostele followed by further reduction in the resultant vascular bundles. This study suggests strongly that the "leaf gap" of conifers and other extant gymnosperms is not homologous with that of siphonostelic ferns and strengthens the validity of the view that Pteropsida is an unnatural group. It supports the position that gymnosperms have evolved from progymnosperms rather than from ferns, and the inclusion of ferns and gymnosperms in separate subdivisions or divisions.
\end{abstract}

IT HAS BEEN clearly established that the primary vascular system of a large number of living conifers is composed essentially of longitudinally oriented sympodia, axial bundles from which leaf traces diverge (Namboodiri and Beck, $1968 \mathrm{a}, \mathrm{b})$. While these features are found in all the specimens studied, variations are observed in the number and mode of formation of traces supplying a leaf. Thus in the forms with helical phyllotaxis the trace supplying a leaf is single at the point of origin (Namboodiri and Beck, 1968a), whereas in species with opposite leaves two traces originating from two different bundles are found to fuse to form the single strand supplying a leaf, thus giving rise to a reticulate vascular architecture. Some arguments have been presented in part II of the study (Namboodiri and Beck, 1968b) suggesting that the open system of the genera with helical leaf arrangement is primitive and the closed, reticulate system of conifers with opposite phyllotaxis is derived. This implies that the single-trace condition characteristic of the conifers with helical phyllo-

1 Received for publication 17 July 1967.

This paper is based on part of a Ph.D. thesis by the first author.

This study has been supported in part by National Science Foundation grant GB-3038 to C. B. Beck.

${ }^{2}$ Formerly known as G. Kadambari Kumari. Present address: Genetics Program, University of North Carolina, Chapel Hill, North Curolina 27514. taxis is the primitive condition, a view that supports the observations of Pant and Mehra (1964). It also suggests the possibility that the leaf gap of conifers is not homologous with that of the siphonostelic ferns.

These conclusions would be of greater phylogenetic significance if they could be applied to the gymnosperms as a whole, especially the extinct forms. A knowledge of the primary vasculature of fossil gymnosperms is necessary in order to draw any valid conclusions about long-range stelar evolution and homology of structures. It is with these goals in mind that the survey reported herein has been made. Such a survey presents several problems. Shoot apices of woody plants, in which the primary vasculature is clearly discernible, are seldom fossilized. Therefore, the main source of information about the primary vascular system is the stem with secondary growth. But when the maturation of the xylem is endarch it is difficult to discern accurately the details of the primary vascular system. Thus genera characterized by mesarch or exarch development of primary xylem provide most of the data for this study.

Among living conifers the number of traces that supply a single leaf may not be the same at nodal levels as at subnodal levels. In the Abietineae, for example, the trace is single at the subnodal levels, but double at the nodal level, 
and in many Cupressaceae it is double at the subnodal levels and single at the nodal level. In order to make this comparison of the primary vascular systems of living and fossil gymnosperms valid, the nature of the leaf trace has been consistently compared at the point of its origin at a subnodal level. Consequently, some fossil genera have not been considered because such information is unavailable.

SURVeY OF PRIMARY VASCUlaR SYSTEMSCenozoic and Mesozoic gymnosperms-Little or nothing is known about the primary vasculature of Cenozoic and Mesozoic conifers and cycads. In the Cycadeoidales, however, the origin of the leaf vascular supply from a eustele as a single trace has been described in Cycadeoidea ingens by Arnold (1947), in C. utopiensis by Delevoryas (1960), both from the Jurassic, and in Monanthesia magnifica, an Upper Cretaceous cycadeoid, by Delevoryas (1959). The vascular system in $C$. utopiensis and $M$. magnifica and, presumably, in other cycadeoids, is complicated by a system of cortical bundles that branch from leaf traces. The cone vascular supply is derived from the cortical bundles (Delevoryas, 1959, 1960).

Paleozoic gymnosperms-In the Cordaitales, considered to be closely related to the Coniferales, the leaf trace is seen as two bundles in the cortex (Scott, 1923, Fig. 100).

Although in Cordaites there is little information on the number of bundles at the point of trace origin, Cohen and Delevoryas (1959) report that the foliar vascular supply in $C$. validus originates as a single bundle. The condition in the genus is probably the same as that found in Mesoxylon, which is nearly indistinguishable from Cordaites except for the mesarch nature of the leaf traces.

In Mesoxylom lomaxii and $M$. poroxyloides (Scott, 1912, 1923), M. sutcliff (Maslen, 1911), $M$. multirame (Scott, 1918), M. thompsonii (Traverse, 1950), and M. birame (Baxter, 1959), each leaf is described as being supplied with a trace, single at the point of origin, which branches subsequently into two at higher levels. Only in a single species, $M$. platypodium (Maslen, 1930), are the two strands supplying a leaf reported to have independent origin in the primary vascular system.

Some other genera, Mesoxylopsis arberae, Mesopitys tchihatcheff, Antarcticoxylon priestleyi, and Haploxylon rochei which are included under Cordaitales by Scott (1923), also have leaf traces single at the point of their origin.

In Poroxylon boysetii, a Permo-Carboniferous genus which shows a combination of cordaitean leaf structure and Lyginopteris-like stem structure (Scott, 1923), the leaf traces originate singly. The stem bundles are discrete and exarch. The description of the primary body given by
Scott (1923) is as follows: "Each leaf trace on entering the stem from the leaf, runs down 13 internodes before joining the trace of a leaf vertically below it." This description suggests a sympodial vascular system, similar to the condition in modern conifers.

Among the pteridosperms, Tetrastichia bupatides (Gordon, 1938) and Tristichia ovensi (Long, 1961) are protostelic, the former with a stele that is cruciform, the latter with a stele that is tri-radiate in section. In both, the vascular supply to lateral appendages originates as single traces that branch from the outermost edges of the stelar ribs.

Heterangium, another Carboniferous pteridosperm and a primitive member of the Lyginopteridaceae, is of particular interest. The primary vascular system of most species is protostelic, the stelar column consisting of large tracheids mixed with abundant parenchyma cells. There is, however, a tendency for medullation of the protostele and formation of fairly discrete peripheral bundles in some species. Delevoryas (1962) describes this trend as follows: "In the stem such as that of $H$. grievii from the Lower Carboniferous, the primary xylem is fairly uniform in size and distribution of tracheids except for somewhat smaller elements near the edge of the protostele." He notes further that in "the Upper Carboniferous species $H$. andrei, the tracheids in the center of the protostele are less compactly organized with a predominance of parenchyma. The more compact peripheral xylem strands are fewer in number than are usually found in Heterangium and are quite distinct." He suggests that "a complete conversion of the center part of the stele in a plant such as $H$. andrei to a pith would result in a structure quite similar to that in Lyginopteris" (see also Scott, 1923; Arnold, 1947).

I.eaf traces depart from the surface of the stele in Heterangium. The trace is single at the point of origin in $H$. andrei, $H$. grievii, $H$. sturii, $H$. alatum, H. schusteri, $H$. polystichum, and $H$. minimum as described by Scott (1923) and Arnold (1947). But in a small section of the genus, known as the polyangium section, with four species, $H$. tiliaeoides, $H$. shorense, $H$. lomaxii, and $H$. americanum, the bundles supplying a leaf are described as double at the point of their origin (Scott, 1923; Andrews, 1945).

Another lyginopterid, the Carboniferous species Lyginopteris oldhamia, has a clearly understood primary vasculature and leaf trace system. A large pith is surrounded by mesarch vascular bundles, all of which are sympodia producing single leaf traces at intervals. Scott (1923) describes the stem thus: "Every leaf trace on reaching the margin of the pith fuses with the nearest circummedullary strand .... The strands which thus divide and give off the successive leaf traces may be called the reparatory strands, 
as they repair the gap left by the outgoing traces. In other words, each reparatory strand constitutes a sympodium, built up of the bases of successive leaf traces." The remarkable similarity of the so-called reparatory strands to the continuing sympodial bundles found in conifers is extremely interesting.

Very similar to Lyginopteris is a new genus of pteridosperms, Callistophyton (Delevoryas and Morgan, 1954). The mode of origin of leaf trace and reparatory strand in C. poroxyloides is nearly identical with that in Lyginopteris.

The Medulloseae, differing in stelar structure from other pteridosperms, has been most recently studied in detail by Stewart and Delevoryas (1952) and Delevoryas (1955). The vascular system of the group is characterized as being polystelic in most species but has been described as protostelic in Sutcliffia by Scott (1906) and DeFraine (1912). In Carboniferous species of Medullosa the stelar system consists usually of several vascular columns, each consisting of a protostele surrounded by variable amounts of secondary xylem and phloem (Delevoryas, 1955). Although there is evidence of both branching and fusion of these columns in some specimens, most show no interconnection over long distances.

The nature of leaf trace origin is not entirely clear in this group. DeFraine (1912) considered the "meristeles" that branched from the central protostele of Sutcliffia to proliferate into the numerous strands supplying a leaf. It is not elear, however, whether the entire vascular sispply to a leaf was derived from one or several of these traces (stelar branches).

Stewart and Delevoryas (1952) and Delevoryas (1955) have shown that in some Carboniferous species of Medullosa the leaf vascular supply originates as many separate strands, each branching from the same vascular column but at slightly different levels. It is obvious that in both Sutcliffia and Medullosa the leaf vascular supply originates as one or more branches of a larger vascular column and diverges outward in a radial plane with no leaf gaps being formed.

The stelar structure of Permian species of Medullosa is more complex than that of the Carboniferous species, being characterized by centrally located vascular columns surrounded by a continuous or a discontinuous cylinder (or cylinders) of primary and secondary vascular tissues (Delevoryas, 1955). Origin of the leaf vascular supply is apparently similar to that of the Carboniferous forms.

The Calamopityeae, a group of Upper Devonian and Lower Carboniferous plants, are similar to the lyginopterid pteridosperms in stem structure. Since, however, their fructifications are unknown, it is not clear whether they were primitive gymnosperms or progymnosperms. Of the seven genera in the family, the Upper Devonian genus Stenomyelon is considered to be the most primitive by Read (1937). The genus is interesting because the stele shows tendencies of medullation and dissection from a protostelic condition. Stenomyelon tuedianum has a true protostelic primary structure, appearing 3-lobed in transverse section, with traces diverging radially from the longitudinal ribs. The vascular supply to lateral appendages originates as a single trace. Stenomyelon muratum (Read, 1937) has a highly parenchymatous stele. The leaf trace system which, likewise, originates as a single strand soon bifurcates. Stenomyelon tripartitum shows a further tendency for medullation and also for longitudinal dissection. Thus the stele which appears distinctly 3-parted is referred to by Scott (1923) as a "triplice of reparatory strands." Single traces originate from the outermost edge of each strand and diverge along a radial plane in a typically protostelic manner.

The best known genus of the group is Calamopitys, composed of seven species. The stem shows a mixed pith surrounded by mesarch bundles and exhibits the same tendency of medullation and definition of peripheral bundles as in Stenomyelon. In species with clearly defined, peripheral vascular bundles, each bundle is a sympodium producing a reparatory strand and leaf traces (Scott and Jeffrey, 1914; Read, 1937).

Another genus of Calamopityaceae is Eristophyton with three species, $E$. fascicularis, $E$. beinertiana (Read, 1937), and E. waltoni (Lacey, 1953). The leaf trace is single in all these and the primary wood is described as being composed of strands which give rise to leaf traces and reparatory strands at intervals. Lacey (1953) notes that following the bifurcation of a bundle of the stem into a leaf trace and a reparatory strand, the latter swings into the pith, and higher up, prior to the formation of the next bifurcation of the bundle (to form a leaf trace and a reparatory strand), moves to the periphery of the pith and comes in contact with the secondary xylem. The only genus of the family which shows a double leaf trace from the beginning is Diichnia kentuckiensis. This, however, is considered to be an advanced type by Read (1937).

In this large group of plants of problematic taxonomic affinities, we thus find steles of varying structure that could be interpreted as representing several stages in the evolution of the stele from a typical protostele to a medullated condition with the primary vascular system dissected and defined as reparatory strands and leaf traces, a condition similar to the early seed plants and modern gymnosperms.

Probable progenitors of gymnosperms-Progymnospermopsida (Beck, 1960) is an assemblage of Devonian and Lower Carboniferous plants which are pteridophytic in their reproduction, but they show many unmistakable features of gymno- 
sperms. Under this group Beck has included Pityales, Protopityales, and Aneurophytales. It is possible that the Calamopityeae, described above, may also belong in this group.

The Pityales contain three genera: Pitys, Archaeopteris (Callixylon), and Archaeopitys. Pitys dayi, described by Gordon (1935), has a primary vascular structure similar to that of Lyginopteris with a large pith bounded by vascular bundles, each bundle branching at regular intervals and giving rise to a single trace and a continuing reparatory strand. Callixylon, the stem of Archaeopteris, is characterized by a large pith surrounded by a number of mesarch primary xylem strands, each of which divides into two bundles lying in the same radial plane. The outer strand diverges outward as the single leaf trace, and the inner continues longitudinally as the reparatory strand without leaving any leaf gap (Arnold, 1930). A similar stelar structure characterizes Archaeopitys (Scott and Jeffrey, 1914; Scott, 1923). This condition is similar to that of Pitys, Lyginopteris, etc., but it is worthy of notice that there is a difference in the position of the reparatory strand in relation to the departing leaf trace in Lyginopteris and Pitys as compared with Archaeopteris and Archaeopitys. In the two former, the trace and reparatory strand are initially oriented side by side in the same tangential plane (i.e., along the same circumference) in contrast to their orientation in the same radial plane in the latter. Thus in Archaeopteris" and Archaeopitys the reparatory strand does not altemate with the leaf trace but is placed directly opposite to it. This strongly recalls the condition in Stenomyelon and Calamopitys wherein the leaf trace simply diverges radially from the ribs of the protostele, or from a peripheral vascular bundle.

Unlike most progymnosperms, Protopitys scotica is described by Walton (1957) as possessing a leaf trace formed by the fusion of two strands.

Aneurophytales, considered by Beck (1960) to be primitive progymnosperms, is a group of Middle to Upper Devonian woody plants with triarch or tetrarch protostelic stems with considerable secondary growth. These plants produced complex branch systems which apparently functioned as leaves. The plants Aneurophyton and Tetraxylopteris (Beck, 1957) have many psilophytic characters. The traces to lateral appendages which, in form, resemble the primary vascular column of the parent axis, branch from the ribs of the stele. This condition recalls that of Stenomyelon. The primary structure of these plants could represent the basic type from which the various patterns have diverged.

Discussion AND conclusions-This survey of the fossil record has shown the great antiquity in gymnosperms and their probable precursors of the nodal structure in which the vascular supply to a leaf or lateral branch system originates as a single trace. Very few species (Mesoxylon platypodium, the small polyangium section of Heterangium, Diichnia kentuckiensis, Protopitys scotica and, at least, several medullosans) are characterized by a vascular supply originating as two or more independent traces. The prevalence of the single-trace condition in the majority of these extinct plants suggests strongly that this condition is more primitive and the other derived from it, a view shared with Pant and Mehra (1964). This furthermore, supports our earlier view (Namboodiri and Beck, 1968b) that the single-trace origin of leaf vasculature is primitive in the living Coniferales. It should be noted that this conclusion is at variance with that of Marsden and Bailey (1955) and Bailey (1956). These authors have suggested that the two-trace node is primitive in the Pteropsida. At least in the case of gymnosperms, this does not seem to be the case. The vast majority of living and extinct gymnosperms have only a single trace at the point of origin. Further, the suggestion of Bailey that the single-trace condition has resulted from xerophytic reduction of the foliage runs counter to the fact that primitive gymnosperms like Lyginopteris, Heterangium, etc., and progymnosperms like Archaeopteris, have, despite their large leaves, only a single leaf trace at the point of origin.

This survey clearly suggests also that the sympodial vascular pattern characteristic of living conifers (Namboodiri and Beck, 1968a,b) exists also in many of the primitive gymnosperms and progymnosperms. The sympodial pattern is characterized by the division of each bundle in the stem into two branches, one, a trace, and the other, referred to in the literature as the reparatory strand, which is identical with the sympodial segment (a term introduced in part I of the present study; Namboodiri and Beck, 1968a) of the primary vascular system of modern conifers. However, in the fossil record two slightly different modes of bifurcation of a bundle in the stem to form the trace and the reparatory strand are described. Bifurcation of vascular bundles in some progymnosperms like Archaeopteris and Archaeopitys, and genera like Stenomyelon, Eristophyton, and Calamopitys of the Calamopityaceae results in two bundles arranged in a radial file, the outer departing as the trace and the inner continuing as the reparatory strand. This mode of trace formation, it should be emphasized, leaves no gap in the primary vascular cylinder. A division of the bundle giving rise to a trace and a reparatory strand initially placed tangentially, as in modern forms, is seen in progymnosperms such as Pitys, pteridosperms such as Callistophyton and Lyginopteris, and Cordaitales such as Poroxylon, and Mesoxylon. As these two types of bifurcation of a bundle occur in possibly closely related forms 
such as Calamopitys and Lyginopteris or Archaeopteris and Mesoxylon, these may be regarded as phylogenetically related conditions.

This survey has also provided evidence for the derivation of the sympodial pattern of the vasculature directly from a protostelic condition. Possible transitional stages in such a changeprogressive medullation to form the pith and the definition of the peripheral region into discrete bundles which represent reparatory strands giving rise to traces at intervals-occur in the well-known genera Stenomyelon, Calamopitys, and Heterangium. The direct derivation of the sympodial pattern from the protostelic condition implies that the emergence of the former from the latter did not involve intervening stages such as overlapping of leaf gaps in a siphonostele and the consequent dissection of the stele.

This is in conflict with the view of Jeffrey $(1899,1902,1917)$ who suggested that from the basic protostelic condition the first step in stelar evolution was the formation of a siphonostele. He argued that the siphonostele is developed phylogenetically by the enclosure of cortical tissue within the stele to form the pith with the correlated appearance of leaf gaps, that is, interruptions in the wall of the tubular stele above the points of departure of leaf traces. Because of the presumed extrastelar origin of the pith, he conceived of the amphiphloic siphonostele as the primitive form. He established the occurrence of foliar lacunae, or leaf-gaps, as one of the characteristic features of the siphonostele in Filicales, gymnosperms, and angiosperms. From the amphiphloic siphonostele, he derived all the other stelar types of these groups by subsequent reduction and loss of inner phloem and endodermis accompanied by further reduction and specialization due to "overlapping leaf gaps" whereby the original tubular condition is assumed to be practically lost. In this way he derived the collateral vasculature characteristic of gymnosperms and angiosperms, and concluded that the gymnosperms are derived from ferns. To quote his own words (Jeffrey, 1917), "It is now clear . . that the lower gymnosperms have come from the Filicales as a result of the simplification and reduction of the primary structures of the stele of the stem on the one hand, accompanied by the marked development of secondary fibrovascular tissues on the other."

The anatomical evidence presented by Jeffrey for the above conclusion consists of: (1) a single instance in a specimen of Lyginopteris of some indication of internal secondary phloem, (2) the occurrence of internal secondary wood in Lyginodendron robustum (Cycadoxylon robustum; see Scott, 1923, p. 229), and (3) the occurrence of internal secondary xylem and phloem in Cycadoxylon fremyii, which he claimed to be closely related to Lyginodendron (Lyginopteris) (Jeffrey, 1902, 1917).
In view of the numerous members of the Lyginopteridaceae without these features, the weight given to these rare occurrences seems to be unwarranted. As regards the inner secondary wood and phloem, their occurrence in a few members may be regarded as probably the result of a response to injury of the stem (Scott, 1923, p. 41). Therefore, the data cited by Jeffrey do not seem to bridge the wide gap existing between the stelar condition in ferns and the typical collateral
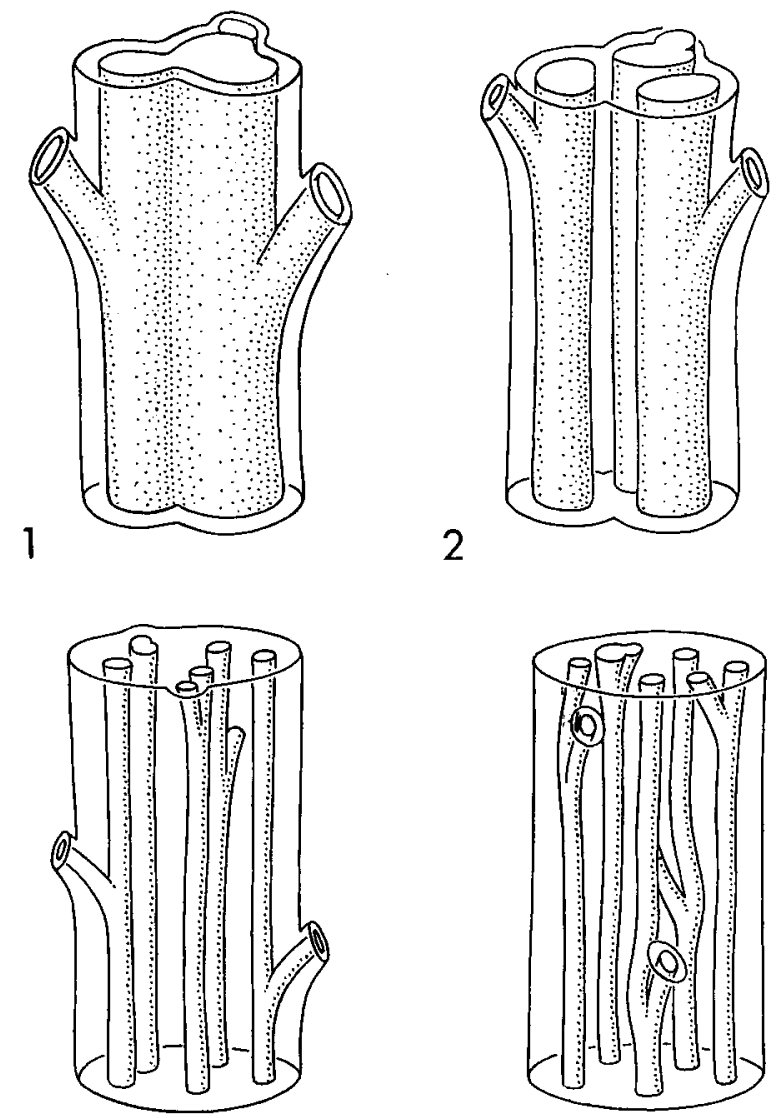

3

4

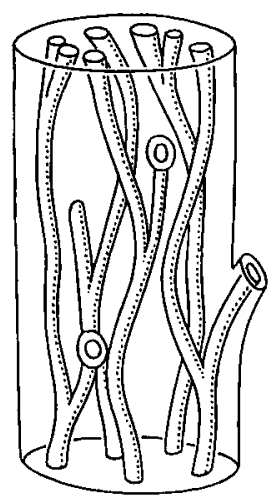

5 
condition of the vasculature in pteridosperms and other gymnosperms.

Further, if Jeffrey's interpretation is correct, the vascular system of such ancient plants as Archaeopteris, Lyginopteris, Callistophyton, Mesoxylom, and others with a primary vascular system in the form of discrete strands surrounding a large pith, have to be thought of as having been derived from an original tubular stele by dissection through the intervention and overlapping of leaf gaps of the fern type accompanied by reduction and loss of internal phloem and endodermis. But in Archaeopteris as well as in Archaeopitys the large bundle supplying the leaf (or lateral branch system) simply branches radially from a vascular bundle in the stem. The inner reparatory strand continues its vertical course without any interruption. The same may be said about Pitys, Callistophyton, Lyginopteris, Mesoxylon, and Poroxylon, although they slightly differ from Archaeopteris in the position taken by the reparatory strand in relation to the leaf trace as previously noted.

There is no good evidence on which to interpret the vascular system of these plants, the extant conifers and other gymnosperms, in terms of a siphonostele having become dissected by overlapping of leaf gaps as proposed by Jeffrey.

Another difficulty with the suggestion that the vascular pattern of gymnosperms has been derived from that of the ferns is that it is inconsistent with the geological data available. The pteridâspermous genera Heterangium and Lyginopteris are often compared with modern Gleichenia and Osmunda as showing possible relationships in the vascular pattern. Such a comparison is baseless, for as Scott $(1923$, p. 61-62) has pointed out: "Though both Gleicheniaceae and Osmundaceae have a fairly long geological history, we may say with some confidence that neither group as we now know it had come into existence at the time when Heterangium and Lyginopteris flourished. The oldest known Osmundaceae, of Permian age, had a stem structure quite different from that of
Lyginopteris. It is impossible to suppose that there was any affinity between the Lyginopterideae and the later or recent Ferns which we arbitrarily compare with them."

There have been no recent paleobotanical discoveries which necessitate a modification of Scott's view.

Because of the above-mentioned difficulties, the proposition that the sympodial pattern of collateral vascular bundles found in gymnosperms and progymnosperms has been derived by dissection of a siphonostele seems to be untenable.

A more probable trend of stelar evolution seems to be one that is consistent with the suggestion of Beck (1960, 1962), that the gymnosperms have evolved from the pteridophytic progymnosperms which, in turn, may have evolved directly from some psilophytic group. The major trend of stelar evolution in these groups appears to be characterized by the evolution of the sympodial pattern of the primary vascular system directly from the protostelic condition through the following successive stages.

1. The primitive condition, i.e., the protostelic condition, in which traces to appendages diverge radially from the outer surface of the stelar column as shown in Fig. 1, is exemplified by any of the forms such as Aneurophyton, Tetraxylopteris, Stenomyelon tuedianum, Tetrastichia, and Tristichia which appear in the geologic column between Middle Devonian and Lower Mississippian.

2. From this primitive condition there is a tendency for gradual dissection of the stele into longitudinal columns with consequent medullation and later definition of the peripheral region into more discrete strands which act as sympodia. This derived stage is shown in Fig. 2, 3. At this stage leaf trace origin, essentially identical with that of the protostelic stage, results from a division of a sympodium which gives rise to an outer leaf trace and an inner continuing reparatory strand, both radially aligned in the stem. This stage is represented by any of the forms such as

Fig. 1-5. Diagrams illustrating a probable trend of evolution of the primary vascular system of gymnosperms and progymnosperms.-Fig. 1. The basic protostelic condition with a massive 3-ribbed stele. Traces to appendages diverge radially from the longitudinal ribs. Forms showing this pattern are Aneurophyton, Stenomyelon tuedianum, Tristichia, et c.-Fig. 2. A three-stranded vascular system derived by the longitudinal dissection of a protostele such as the one shown in Fig. 1. The traces diverge from the outer margin of the strands by tangential division without forming leaf gaps. Forms showing this pattern are: Stenomyelon muratum, Stenomyelon tripartitum, etc.-Fig. 3. A pattern similar to that of Fir. 2 but with a larger pith and discrete strands near the periphery. At the time of leaf-trace formation, a stelar bundle divides into an outer and an inner bundle, the former diverging as the leaf trace and the latter continuing as the reparatory strand without any leaf gap. Forms showing this pattern are Archaeopteris, Archaeopitys, Calamopitys, etc. -Fig. 4. A dissected vascular system with large pith and discrete strands near the periphery as in Fig. 3 . It differs from the latter in that at the time of leaf-trace formation, a stelar bundle divides initially into two tangentially oriented bundles, a leaf trace and a continuing reparatory strand (sympodial bundle). The forms exhibiting this pattern in the fossil record are Pitys, Lyginopteris, Callistophyton, Poroxylon, etc.-Fig. 5. A pattern similar to that of Fig. 4, but showing the undulating path taken by the axial sympodial bundles during their upward course as seen in the primary vascular system of living conifers with helical phyllotaxis. 
Stenomyelon muratum, Stenomyelon tripartitum, Archaeopteris, Archaeopitys, Calamopitys, and Eristophyton. These forms appear in the geologic column between the Upper Devonian and Lower Mississippian.

3. The next step is a change in the nature of the division of the sympodium from a division resulting in radially arranged bundles (i.e., leaf trace and reparatory strand oriented along the same radius) to a division of the sympodium to form two bundles initially placed tangentially (i.e., oriented along the same circumference). This condition is depicted in Fig. 4, 5 and is characteristic of Pitys, Lyginopteris, Callistophyton, Poroxylon, Mesoxylon, etc., and also the living conifers. These occur in the geologic column between the Lower Mississippian and the Recent. Figure 5 shows, in addition to the initial tangential orientation of the leaf trace and the sympodial segment, the vertical undulating path taken by the sympodial segment during its upward course. This feature is clearly evident in the primary vasculature of the living conifers. ${ }^{3}$

The vascular patterns of Ginkgo (Gunckel and Wetmore, 1946), Ephedra (Marsden and Steeves, 1955), and the reticulate pattern in some conifers with opposite leaves may be seen as modifications of the pattern depicted in Fig. 5 involving an increase in the number of traces supplying a leaf from one to two and change in the direction of divergence of the traces (Namboodiri and Beck, 1968b).

In citing examples of genera that are characterized by the several stelar modifications described above, no genetic relationship between those with a particular stelar type is necessarily implied. On the basis of data and opinion from many sources, it is quite possible that at least two lines of evolution are represented by these genera of progymnosperms and primitive gymnosperms. As recently suggested by Beck (1967), these two lines may diverge from the Aneurophytales, one toward the cycadophytic gymnosperms by way of the Calamopityeae, the other toward the coniferophytic gymnosperms through Archaeopteris and/or related genera.

The first line includes such genera as Stenomyelon, Calamopitys, Heterangium, Lyginopteris, etc. The second includes, among others, Callixylon (Archaeopteris), Archaeopitys, Pitys, Cordaites (Mesoxylon), and living conifers. It is significant that among the genera of each of these groups are represented the several stages in the evolution of the stele as proposed above. This suggests that the sympodial stelar pattern evolved similarly and independently in both evolutionary lines.

3 The data from the fossil record do not indicate whether or not the reparatory strands (axial sympodial bundles) in the extinct plants take a vertically undulating path as in living conifers. The scarcity of fossil axes with intact primary vascular structure containing several nodes accounts for the lack of such data.
Although stelar evolution in the Medulloseae has been given an entirely different interpretation by Stewart and Delevoryas (1952) and Delevoryas (1955), the stelar structure of this group also can be interpreted, with some modification, to have originated as described above.

From a form such as Sutcliffia, or even from a lyginopterid such as Heterangium, the medullosan stelar structure could have originated by simple longitudinal dissection of a protostele followed by the establishment of secondary activity around each resulting bundle in the system. Unlike other gymnosperms, the stelar bundles of the Carboniferous medullosans are not peripherally located around a central pith, a difference that could have been related to the early establishment of cambial activity around each bundle.

Detailed evidence for the concept of evolution of the Medulloseae from protostelic lyginopterid ancestors has been presented by $\operatorname{Scott}(1906,1923)$ and DeFraine (1912). Their views are consistent with our hypothesis regarding the origin of the medullosan stelar system.

Stewart and Delevoryas (1952) and Delevoryas (1955) suggest, alternatively, the establishment of "polystely" in this group by fusion of separate axes of a hypothetical, dichotomously branching ancestor. Delevoryas (1955) has also suggested that the Devonian Cladoxylales might be ancestral to the Medulloseae. We believe, however, that the similar stelar structure of the two groups was, more likely, the result of parallel evolution. Our view seems to be supported by the recent discovery of cladoxylalean anatomy in Pseudosporochnus (Leclercq and Banks, 1962) and in Calamophyton (Leclercq and Schweitzer, 1965), forms characterized by a morphology very different from that of the Medulloseae.

Detailed trends of structural modification of the vascular system in the Permian Medulloseae and evidence for the possible origin of the stelar structure of the Cycadales from this group are presented by Delevoryas (1955), Worsdell (1906), and others (see Delevoryas, 1955) and will not be repeated in this paper.

If it is accepted that the primary vascular system of progymnosperms and gymnosperms has evolved as here proposed, it becomes clear that the "leaf gaps" of gymnosperms are not homologous with those of ferns. Consequently, the term leaf gap, when applied to the parenchymatous, interfascicular region opposite the diverging leaf trace in gymnosperms should be used in a purely descriptive sense.

Taxonomic implications-The group Pteropsida as proposed by Jeffrey is characterized by the occurrence of abaxial sporangia, megaphyllous leaves, and leaf gaps. Florin's work (1938-1945, 1951) on the female cones of conifers resulted in a loss of significance of the abaxial sporangia as a unifying character. Our work (Namboodiri 
and Beck, 1968a, b, and the present study) has shown that the leaf gaps of gymnosperms are not homologous with those of ferns. As regards the occurrence of megaphyllous leaves, it may be noted that, if megaphylly is defined primarily in terms of the relationship of the leaf trace or traces to well-defined leaf gaps of the fern type, the absence of such gaps in gymnosperms and progymnosperms suggests that their leaves are not megaphyllous in this sense. Thus the characters, abaxial sporangia, occurrence of leaf gaps, and megaphyllous leaves distinguished by their primary association with leaf gaps of the fern type, fail to apply equally to ferns, gymnosperms and angiosperms. Hence, one cannot avoid questioning the validity of grouping ferns, gymnosperms and angiosperms in Pteropsida, and at the same time support is provided for those who have abandoned Pteropsida and raised the groups formerly included within it to higher categories.

\section{LITERATURE CITED}

ANdrews, H. N., JR. 1945. Contributions to our knowledge of American Carboniferous floras VII. Some pteridosperm stems from Iowa. Bot. Gaz. 110: $13-41$.

Arnold, C. A. 1930. The genus Callixylon from the Upper Devonian of Central and Northwestern New York. Papers Mich. Acad. 11: 1-50.

- 1947. An introduction to paleobotany. MeGraw-Hill, New York.

Bailey, I. W. 1956. Nodal anatomy in retrospect. J. Arnold Arbor. 37: 269-287.

Baxter, R. W. 1959. A new cordaitean stem with paired axillary branches. Amer. J. Bot. 46: 163-169.

Beck, C. B. 1957. Tetraxylopteris schmidtii gen. et sp. nov., a probable pteridosperm precursor from the Devonian of New York. Amer. J. Bot. 44: 350-367.

- 1960. The identity of Archaeopteris and Callixylon. Brittonia 12: 351-368.

1962. Reconstructions of Archaeopteris, and further consideration of its phylogenetic position. Amer. J. Bot. 49: 373-382.

1967. On the origin of gymnosperms. Taxon 15: $337-339$.

Cohen, L. M., and T. Delevoryas. 1959. An occurrence of Cordaites in the Upper Pennsylvanian of Illinois. Amer. J. Bot. 46: 545-549.

DeFraine, E. 1912. On the structure and affinities of Sutcliffia, in the light of a newly discovered specimen. Ann. Bot. 26: 1031-1066.

Delevoryas, T. 1955. The Medulloseae-structure and relationships. Palaeontographica 97B: 114-167.

- 1959. Investigations of North American Cycadeoids: Monanthesia. Amer. J. Bot. 46: 657-666.

1960. Investigations of North American $\mathrm{Cy}$ cadeoids: Trunks from Wyoming. Amer. J. Bot. 47: 778-786.

-1962. Morphology and evolution of fossil plants. Holt, Rinehart and Winston, New York.

—_ AND J. Morgan. 1954. A new pteridosperm from the Upper Pennsylvanian deposits of North America. Palaeontographica 96B: 12-23.

FloRin, R. 1938-1945. Die Koniferen des Oberkarbons und des Unteren Perms. Palaeontographica 85B: Pt. 1-8.

- 1951. Evolution in Cordaites and conifers. Acta Hort. Berg. 15: 285-388.

Gondon, W. T. 1935. The genus Pitys. Trans. Roy. Soc. Edinburgh 58: 279-311.

- 1938. On Tetrastichia bupatides: A Carboniferous pteridosperm from East Lothian. Trans. Roy. Soc. Edinburgh 59: 351-370.

Gunckel, J. E., and R. H. Wetmore. 1946. Studies of development in long shoots and short shoots of Ginkgo biloba L. II. Phyllotaxis and organization of the primary vascular system: primary phloem and primary xylem. Amer. J. Bot. 33: 532--543.

JEFFREY, E. C. 1899. The morphology of the central cylinder in angiosperms. Trans. Can. Inst. 6: 599-636.

1902. The structure and development of the stem in the Pteridophyta and gymnosperms. Phil. Trans. Roy. Soc. London B. 1902. 195. 119-146.

. 1917. The anatomy of woody plants. Univ. Chicago Press, Chicago.

LaCEY, W. S. 1953. Scottish Lower Carboniferous plants: Eristophyton waltoni sp. nov. and Endoxylon zonatum (Kidston) Scott from Dunbartonshire. Ann. Bot. N. S. 17: 579-596.

LeclercQ, S., ANd H. P. Banks. 1962. Pseudosporochnus nodosus sp. nov., a Middle Devonian plant with cladoxylalean affinities. Palaeontographica 110B: $1-34$.

- AND H. J. Schweitzer. 1965. Calamophyton is not a sphenopsid. Bull. Acad. Roy. Belgique 11: 1394-1402.

Long, A. G. 1961. Tristichia ovensi gen. et sp. nov., a protostelic Lower Carboniferous pteridosperm from Berwickshire and East Lothian, with an account of some associated seeds and cupules. Trans. Roy. Soc. Edinburgh 64: 477-489.

Marsden, M. P. F., And I. W. Bailey. 195̄. A fourth type of nodal anatomy in dicotyledons, illustrated by Clerodendron trichotomum Thunb. J. Arnold Arbor. 36: 1-51.

$\longrightarrow$, And T. A. STeeves. 1955. On the primary vascular system and the nodal anatomy of Ephedra. J. Arnold Arbor. 36: 241-258.

Masten, A. J. 1911. The structure of Mesoxylon sutcliffi. Ann. Bot. 25: 381-414.

- 1930. The structure of Mesoxylon platypodium and Mesoxyloides. Ann. Bot. 44: 503-533.

Namboodiri, K. K., And C. B. BeCK. 1968a. A comparative study of the primary vascular system of conifers. I. Genera with helical phyllotaxis. Amer. J. Bot. 55: 447-457.

——, AND —. 1968b. A comparative study of the primary vascular system of conifers. II. Genera with opposite and whorled phyllotaxis. Amer. J. Bot. 55: 458-463.

Pant, D. D., And B. Mehra. 1964. Nodal anatomy in retrospect. Phytomorphology 14: 384-387.

READ, C. B. 1937. The flora of the New Albany shale. Part 2. The Calamopityeae and their relationships. U. S. Geol. Surv. Prof. Paper. 186 E. 81-104.

Scotr, D. H. 1906. On Sutcliffia insignis, a new type of Medulloseae from the Lower Coal-Measures. Trans. Linn. Soc. London 7: 45-68.

- 1912. The structure of Mesoxylon lomaxii and Mesoxylon poroxyloides. Ann. Bot. 26: 1011-1030.

1918. The structure of Mesoxylon multirame. Ann. Bot. 32: 437-457. 
1923. Studies in fossil botany. Vol. 2. London. AND E. C. Jefrrer. 1914. On fossil plants, showing structure, from the base of the Waverley Shale of Kentucky. Phil. Trans. Roy. Soc. 205B: 315-373.

Stewart, W. N., and T. Delevoryas. 1952. Bases for determining relationships among the Medullosaceae. Amer. J. Bot. 39: 505-516.

Traverse, A. 1950. The primary vascular body of
Mesoxylon Thompsonii, a new American Cordaitalean. Amer. J. Bot. 37: 318-325.

Walton, J. 1957. On Protopitys (Göppert): with a description of a fertile specimen Protopitys Scotica sp. nov. from the Calciferous sandstone series of Dunbartonshire. Trans. Roy. Soc. Edinburgh 63: 333-340.

Worsdell, W. C. 1906. The structure and origin of the Cycadaceae. Ann. Bot. 20: 129-15̄o. 